\title{
Evaluation of Inotropic Activity of Fluorobenzene Derivative Using an Isolated Rat Heart Model
}

\author{
Figueroa-Valverde Lauro ${ }^{1, *}$, Hau-Heredia Lenin ${ }^{1}$, García-Cervera Elodia $^{1}$, López-Ramos Maria ${ }^{1}$, \\ Díaz-Cedillo Francisco ${ }^{2}$, Pool-Gómez Eduardo ${ }^{1}$, Rosas-Nexticapa Marcela ${ }^{3}$, Herrera-Meza Socorro ${ }^{4}$, \\ Mateu-Armand Virginia ${ }^{3}$, Cauich-Carrillo Regina ${ }^{1}$, Euan-Hau Saidy ${ }^{1}$ \\ ${ }^{1}$ Laboratory of Pharmacochemistry, Faculty of Chemical Biological Sciences, University, \\ University Autonomous of Campeche, México \\ ${ }^{2}$ Escuela Nacional de Ciencias Biológicas del Instituto Politécnico Nacional, \\ Prol. Carpio y Plan de Ayala s/n Col. Santo Tomas, México \\ ${ }^{3}$ Faculty of Nutrition, Universidad Veracruzana, México \\ ${ }^{4}$ Institute in Psychological Research, Universidad Veracruzana, México
}

Copyright $\bigcirc 2018$ by authors, all rights reserved. Authors agree that this article remains permanently open access under the terms of the Creative Commons Attribution License 4.0 International License

\begin{abstract}
There are studies which indicate that some fluorobenzene derivatives have inotropic activity; nevertheless, the cellular site and mechanism of action at cardiovascular level is very confusing. To clarify these phenomena in this study, a new fluorobenzene derivative was synthesized to evaluate its biological activity on perfusion pressure and left ventricular pressure. The Langendorff technique was used to measure changes on perfusion pressure and coronary resistance in an isolated rat heart model in absence or presence of the fluorobenzene derivative $[0.001 \mathrm{nM}]$. Additionally, to characterize the molecular mechanism involved in the inotropic activity induced by the fluorobenzene derivative was evaluated by measuring left ventricular pressure in absence or presence of following compounds; ouabain, digoxin, levosimendan, cyclopiazonic acid and thapsigargin. The results showed that the fluorobenzene derivative significantly increased the perfusion pressure and coronary resistance in comparison with the control conditions. Additionally, other data indicate that fluorobenzene derivative increase perfusion pressure in a form similar to ouabain and digoxin; however, this effect was different compared with levosimendan. Other results showed that biological activity induced by the fluorobenzene on left ventricular pressure was significantly inhibited by both cyclopiazonic acid [50 $\mathrm{mM}]$ and thapsigargin $[300 \mathrm{mM}]$. These data suggest that positive inotropic activity induced by the fluorobenzene on perfusion pressure and left ventricular pressure was via changes of biological activity both Na,K-ATPase and $\mathrm{Ca}^{+2}$-ATPase. This phenomenon is a particularly interesting because the positive inotropic activity induced by this fluorobenzene derivative involves a molecular mechanism different in comparison with other positive inotropic drugs.
\end{abstract}

Keywords Fluorobenzene, Derivative, Inotropic Activity, ATPase

\section{Introduction}

Congestive heart failure is one of the main health problems worldwide [1-3]. Since several years ago several drugs with positive inotropic activity have been used for the treatment of congestive heart failure $[4,5]$. For example, the use of digoxin (ATP-ase inhibitor) in patients with heart failure; however, its narrow therapeutic window and even slight exposure changes have been associated with adverse reactions; this has resulted in close monitoring of digoxin serum levels in patients with heart failure [6-8]. This problem has resulted in the use of other therapeutic alternatives such as dobutamine (adrenergic agonist); however, its poor oral bioavailability results in this drug being administered intravenously [9]. This has led to studies comparing the effect of dobutamine with levosimendan (positive inotropic, calcium sensitizer); the results showed an improvement in hemodynamic function with levosimendan compared to the group treated with dobutamine [10]. However, it has been observed that high doses of levosimendan in patients with episodes of myocardial infarction may induce changes in the inotropic effect by inhibiting the activity of some phosphodiesterases [11]. In this latter aspect, it is important to mention that there are other types of drugs with positive inotropic activity, which act by inhibiting the isoenzyme III of phosphodiesterase's [12-14]. For example, the milrinone at a dose of $0.75 \mu \mathrm{g} / \mathrm{kg}$ per minute increased cardiac output and reduce systemic vascular resistance in patients with 
heart failure [15]; however, it can increase the incidence of ischemic heart disease and ventricular arrhythmias in a dose-dependent manner [16]. In addition, other drugs for heart failure have been used such as angiotensin converting enzyme inhibitors and spironolactone [17-20]; however, there data which indicate that the abrupt increase in the prescription of spironolactone can induce hypercalcemia [21]. All these data have led to the search for new therapeutic alternatives for the treatment of heart failure; for example, a study showed that a spiro cycloalkane one induce positive inotropic activity via phosphodiesterase inhibition in an animal model [22]. Other report showed that the compound OPC-18790 is a positive inotropic and vasodilating agent which increases intracellular cyclic AMP and stimulates intracellular $\mathrm{Ca}^{+2}$ currents in an isolated dog heart model [23]. In addition, a study indicated that the compound YS-49 (1,2,3,4-Tetrahydro-1-(1-naphthalenylmethyl)-6,7-Isoquin olinediol hydrobromide monohydrate) induce positive inotropic activity in rat vascular smooth muscle via nitric oxide synthase inhibition [24]. Other data indicate that showed that a fluorobenzene derivative (piperazino-fluorobenzene) exert both intropic and chronotropic activity in isolated guinea-pig atria preparations via phosphodiesterase's inhibition [25]. All these data show that several compounds can induce inotropic effects in the cardiovascular system; however, there are few reports on the inotropic activity exerted by the fluorobenzene derivatives. To provide more information about this phenomenon, this study was designed to investigate the effects of a fluorobenzene derivative on perfusion pressure and coronary resistance in isolated rat hearts using the Langendorff technique [26]. In addition, to evaluate the molecular mechanism involved in the inotropic activity induced by the fluorobenzene derivative on left ventricular pressure several drugs were used as pharmacological tools.

\section{Methods}

\section{Synthesis Chemical}

\section{General Methods}

All the compounds used in this work were purchased from Sigma-Aldrich Co. Ltd. The melting points for the different compounds were determined on an Electrothermal (900 models). Flash chromatography was performed on silica gel $60(0.040-0.063 \mathrm{~mm}$, Merck). Infrared spectra (IR) were recorded using $\mathrm{KBr}$ pellets on a Perkin Elmer Lambda 40 spectrometer. ${ }^{1} \mathrm{H}$ and ${ }^{13} \mathrm{C}$ NMR spectra were recorded on a Varian VXR-300/5 FT NMR spectrometer at 300 and $75.4 \mathrm{MHz}$ in $\mathrm{CDCl}_{3}$ using TMS as internal standard. EIMS spectra were obtained with a Finnigan Trace GC Polaris Q. spectrometer. Elementary analysis data were acquired from a Perkin Elmer Ser. II
CHNS/0 2400 elemental analyzer.

4,4'-((4-fluoro-1,3-phenylene)bis(oxy))bis(1-allyl-3me- thoxybenzene) (2)

A solution of 2,4-dinitrofluorobenzene (100 mg, 0.54 $\mathrm{mmol})$ eugenol $(212 \mu \mathrm{l}, 1.21 \mathrm{mmol})$, potassium carbonate anhydrous $(50 \mathrm{mg}, 0.36 \mathrm{mmol})$ in $5 \mathrm{ml}$ of dimethyl sulfoxide was stirring for $72 \mathrm{~h}$ to room temperature. The reaction mixture was evaporated to dryness under reduced pressure. After, the residue was purified by crystallization from methanol: water (4:1)

1-\{3-[4-(4-Fluoro-3-\{4-[3-(2-hydroxy-butyl)-cyclobut -2-enylmethyl]-2-methoxy-phenoxy\}-phenoxy)-3-meth oxy- benzyl]-cyclobut-1-enyl\}-butan-2-ol (3)

A solution of 2 ( $200 \mathrm{mg}, 0.48 \mathrm{mmol})$, hexyn-3-ol (160 $\mu \mathrm{l}$, $1.44 \mathrm{mmol})$, Copper (II) chloride anhydrous (200 mg, 1.44 $\mathrm{mmol}$ ), in $5 \mathrm{ml}$ of methanol was stirring for $72 \mathrm{~h}$ to room temperature. The reaction mixture was evaporated to dryness under reduced pressure. After, the residue was purified by crystallization from methanol: hexane: water $(4: 2: 1)$

\section{Biological Methods}

All experimental procedures and protocols used in this investigation were reviewed and approved by the Animal care and use Committee of University Autonomous of Campeche (No. PI-420/12) and were in accordance with the guide for the care and use of laboratory animals [27]. Male Wistar rats; weighing 200-250 g were obtained from University Autonomous of Campeche.

\section{Reagents}

All drugs were dissolved in methanol and different dilutions were obtained using Krebs-Henseleit solution $(\leq$ $0.01 \%, \mathrm{v} / \mathrm{v})$.

\section{Experimental Design}

Briefly, the male rat (200 - $250 \mathrm{~g}$ ) was anesthetized by injecting them with pentobarbital at a dose rate of 50 $\mathrm{mg} / \mathrm{Kg}$ body weight. Then the chest was opened, and a loose ligature passed through the ascending aorta. The heart was then rapidly removed and immersed in ice cold physiologic saline solution. The heart was trimmed of non-cardiac tissue and retrograde perfused via a non-circulating perfusion system at a constant flow rate. The perfusion medium was the Krebs-Henseleit solution $\left(\mathrm{pH}=7.4,37^{\circ} \mathrm{C}\right)$ composed of (mmol); $117.8 \mathrm{NaCl} ; 6 \mathrm{KCl}$; $1.75 \mathrm{CaCl}_{2} ; 1.2 \mathrm{NaH}_{2} \mathrm{PO}_{4} ; 1.2 \mathrm{MgSO}_{4} ; 24.2 \mathrm{NaHCO}_{3} ; 5$ glucose and 5 sodium pyruvate. The solution was actively bubbled with a mixture of $\mathrm{O}_{2} / \mathrm{CO}_{2}(95: 5 / 5 \%)$. The coronary flow was adjusted with a variable speed peristaltic pump. An initial perfusion rate of $15 \mathrm{ml} / \mathrm{min}$ for $5 \mathrm{~min}$ was followed by a $15 \mathrm{~min}$ equilibration period at a perfusion rate of $10 \mathrm{ml} / \mathrm{min}$. All experimental measurements were done after this equilibration period. 


\section{Perfusion Pressure}

Evaluation of measurements of perfusion pressure changes induced by drugs administration in this study were assessed using a pressure transducer connected to the chamber where the hearts were mounted and the results entered into a computerized data capture system (Biopac).

\section{Inotropic Activity}

Contractile function was assessed by measuring left ventricular developed pressure (LV/dP), using a saline-filled latex balloon $(0.01 \mathrm{~mm}$, diameter) inserted into the left ventricle via the left atrium. The latex balloon was bound to cannula which was linked to pressure transducer that was connected with the MP100 data acquisition system.

\section{Biological Evaluation}

First stage

Ischemia/Reperfusion model

After of 15-minute equilibration time, the hearts were subjected to ischemia for 30 minutes by turning off the perfusion system [28]. After this period, the system was restarted and the hearts were reperfused by 30 minutes with Krebs-Henseleit solution. The hearts were randomly divided into 4 major treatment groups with $\mathrm{n}=9$ :

Group I. Hearts were subjected to ischemia/reperfusion but received vehicle only (Krebs- Henseleit solution).

Group II. Hearts were subjected to ischemia/reperfusion and treated with 3-5-dinitrobenzoic acid [0.001 nM] before ischemia period (for 10 minutes) and during the entire period of reperfusion.

Group III. Hearts were subjected to ischemia/reperfusion and treated with the compound 2 $[0.001 \mathrm{nM}]$ before ischemia period (for 10 minutes) and during the entire period of reperfusion.

Group IV. Hearts were subjected to ischemia/reperfusion and treated with the compound $\mathbf{3}$ $[0.001 \mathrm{nM}]$ before ischemia period (for 10 minutes) and during the entire period of reperfusion.

At the end of each experiment, the perfusion pump was stopped, and $0.5 \mathrm{ml}$ of fluorescein solution $(0.10 \%)$ was injected slowly through a sidearm port connected to the aortic cannula. The dye was passed through the heart for 10 $\mathrm{sec}$ to ensure its uniform tissue distribution. The presence of fluorescein was used to demarcate the tissue that was not subjected to regional ischemia, as opposed to the risk region. The heart was removed from the perfusion apparatus and cut into two transverse sections at right angles to the vertical axis. The right ventricle, apex, and atrial tissue were discarded. The areas of the normal left ventricle non risk region, area at risk, and infarct region were determined using the technique reported by [28]
Total area at risk was expressed as the percentage of the left ventricle.

\section{Second Stage}

Effects induced by 3,5-dinitrobenzoic acid or compounds 2 or 3 on perfusion pressure: Changes in perfusion pressure as a consequence of increases in time (3 to $18 \mathrm{~min}$ ) in absence (control) and presence of 3,5-dinitrobenzoic acid or compounds $\mathbf{2}$ or $\mathbf{3}$ at a concentration of $0.001 \mathrm{nM}$ were determined. The effects were obtained in isolated hearts perfused at a constant-flow rate of $10 \mathrm{ml} / \mathrm{min}$.

Evaluation of effects exerted by 3,5-dinitrobenzoic acid or compounds 2 or 3 on coronary resistance: The coronary resistance in absence (control) and presence of 3,5-dinitrobenzoic acid or compounds $\mathbf{2}$ or $\mathbf{3}$ at a concentration of $0.001 \mathrm{nM}$ was evaluated. The effects were obtained in isolated hearts perfused at a constant flow rate of $10 \mathrm{ml} / \mathrm{min}$. Since a constant flow was used changes in coronary pressure reflected the changes in coronary resistance.

\section{Third Stage}

Effects induced by noradrenaline or dobutamine or compound 3 on perfusion pressure via adrenergic. Changes in perfusion pressure as a consequence of increases in time ( 3 to $18 \mathrm{~min}$ ) in absence (control) and presence of the compound $3[0.001 \mathrm{nM}]$ or noradrenaline $[1 \mathrm{nM}]$ or dobutamine $[1 \mathrm{nM}]$ were determined. The effects were obtained in isolated hearts perfused at a constant-flow rate of $10 \mathrm{ml} / \mathrm{min}$.

Effects induced by digoxine or ouabaine or the compound 3 on perfusion pressure via K,Na-ATPase. Biological activity exerted by digoxine $[0.01 \mathrm{nM}]$ or ouabaine $[0.001 \mathrm{nM}]$ or the compound $3[0.001 \mathrm{nM}]$ on perfusion pressure as a consequence of increases in time (3 to $18 \mathrm{~min}$ ). The effects were obtained in isolated hearts perfused at a constant-flow rate of $10 \mathrm{ml} / \mathrm{min}$.

Effect exerted by the compound 3 on left ventricular pressure in presence or absence of cyclopiazonic acid or thapsigargin via $\boldsymbol{C a}^{+2}-$ ATPase. The compound $3[0.001$ to $100 \mathrm{nM}$ ] was administered (intracoronary boluses, $50 \mu \mathrm{l}$ ) and the corresponding effect on the left ventricular pressure was determined. The dose response curve (control) was repeated in the presence of cyplopiazonic acid [50 $\mathrm{nM}$ ] or thapsigargin $[300 \mathrm{nM}]$ (duration of the pre-incubation with cyplopiazonic acid was for a period of $10 \mathrm{~min}$ ).

Evaluation theoretical of activity exerted by compound 3 on both $\mathrm{Na}, \mathrm{K}$-ATPase and $\mathrm{Ca}^{+2}$-ATPase Docking calculations were carried out using Docking Server [29]. The MMFF94 force field [30] was used for energy minimization of ligand molecule using the Docking Server. Gasteiger partial charges were added to the ligand atoms. Non-polar hydrogen atoms were merged, and rotatable bonds were defined. Docking calculations were carried out on the $\mathrm{Na}, \mathrm{K}$-ATPase $(1 \mathrm{KJU})$ [31] and $\mathrm{Ca}^{+2}$-ATPase 
(3WGU) [32] protein models. Essential hydrogen atoms, Kollman united atom type charges, and solvation parameters were added with the aid of AutoDock tools. Affinity (grid) maps of $20 \times 20 \times 20$ - $\AA$ grid points and $0.375-\AA$ spacing were generated using the Autogrid program. AutoDock parameter set and distance dependent dielectric functions were used in the calculation of the Vander Waals and the electrostatic terms, respectively. Docking simulations were performed using the Lamarckian genetic algorithm (LGA) and the Solis and Wets local search method [33]. Initial position, orientation, and torsions of the ligand molecules were set randomly. Each docking experiment was derived from two different runs that were set to terminate after a maximum of 250,000 energy evaluations. The population size was set to 150 . During the search, a translational step of $0.2 \AA$ and quaternion and torsion steps of 5 were applied.

\section{Statistical Analysis}

The obtained values are expressed as average $\pm \mathrm{SE}$, using each heart $(n=9)$ as its own control. The data obtained were put under Analysis of Variance (ANOVA) with the Bonferroni correction factor [34] using the SPSS 12.0 program. The differences were considered significant when $\boldsymbol{p}$ was equal or smaller than 0.05 .

\section{Results}

\section{Chemical Synthesis}

The yielding of compound $\mathbf{2}$ (fluoro-methoxybenzene derivative, Figure 1) was $44 \%$ with melting point of 62-62 ${ }^{\circ} \mathrm{C}$. In addition, the chemical shifts of the spectroscopic analyses of ${ }^{1} \mathrm{H}$ NMR and ${ }^{13} \mathrm{C}$ NMR for the compound $\mathbf{2}$ is showed in the table 1. Finally, the results of mass spectroscopy (EI-MS) (70 electron volts) shown; $\mathrm{m} / \mathrm{z}$ 420.17. Additionally, the elementary analysis data for the the compound $2\left(\mathrm{C}_{26} \mathrm{H}_{25} \mathrm{FO}_{4}\right)$ were calculated $(\mathrm{C}, 74.27 ; \mathrm{H}$, 5.99; F, 4.52; O, 15.22) and found (C, 74.22; H, 5.90).

Other data showed a yield of $67 \%$ for the compound 3 (Fluoro-cyclobutenyl-2-ol derivative, Figure 1) with melting point of $80-82{ }^{\circ} \mathrm{C}$. ${ }^{1} \mathrm{H}$ NMR and ${ }^{13} \mathrm{C}$ NMR spectra for the compound $\mathbf{3}$ are showed in the table 1. Finally, the results of mass spectroscopy (MS) (70 electron volts) shown; $\mathrm{m} / \mathrm{z}$ 616.32. Additionally, the elementary analysis data for the compound $3\left(\mathrm{C}_{38} \mathrm{H}_{45} \mathrm{FO}_{6}\right)$ were calculated $(\mathrm{C}$, 74.00; H, 7.35; F, 3.08, O, 15.56) and found (C, 74.00; H, 7.26).

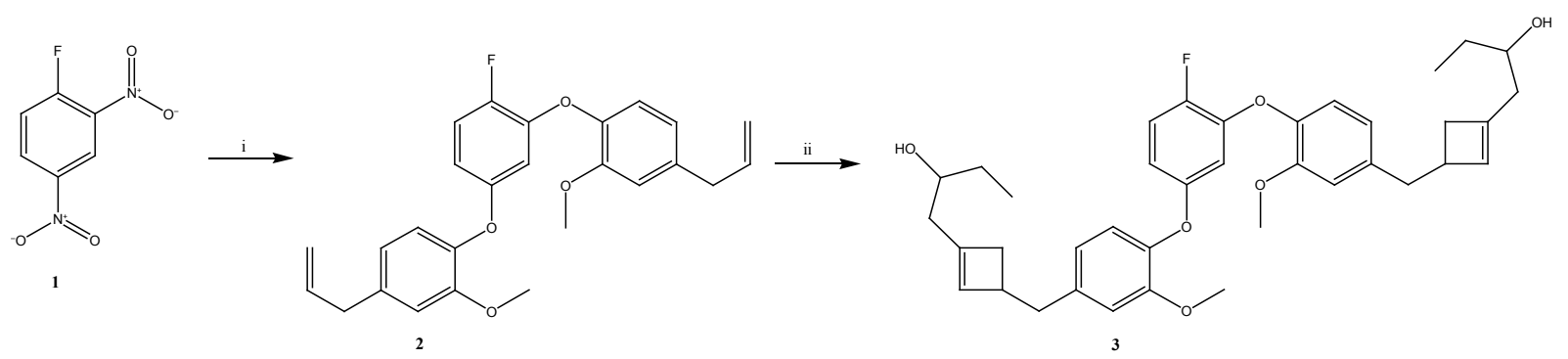

Figure 1. Preparation of the fluoro-cyclobutenyl-2-ol derivative (3). Reaction of 1-fluoro-2,4-dinitro-benzene (1) with eugenol (i) to form the fluoro-di-methoxybenzene derivative (2). Then, 2 was reacted with 1-hexyn-3-ol (ii) to synthesis of $\mathbf{3}$.

Table 1. ${ }^{1} \mathrm{H}$ NMR and ${ }^{13} \mathrm{C}$ NMR spectra for the compound $\mathbf{2}$ and $\mathbf{3}$

\begin{tabular}{|c|c|c|}
\hline & ${ }^{1} \mathrm{H}$ NMR $\left(300 \mathrm{MHz}, \mathrm{CDCl}_{3}\right)$ & ${ }^{13} \mathrm{C}$ NMR $\left(75.4 \mathrm{~Hz}, \mathrm{CDCl}_{3}\right)$ \\
\hline Compound 2 & $\begin{array}{c}\delta_{\mathrm{H}}: 3.30(\mathrm{~m}, 4 \mathrm{H}), 3.80(\mathrm{~m}, 4 \mathrm{H}), 5.02(\mathrm{~d}, \mathrm{~d}, 2 \mathrm{H}), 5.08(\mathrm{~d}, \mathrm{~d}, \\
2 \mathrm{H}), 5.98(\mathrm{~d}, \mathrm{~d}, 2 \mathrm{H}), 6.50-7.18(\mathrm{~m}, 9 \mathrm{H}) \mathrm{ppm} .\end{array}$ & $\begin{array}{c}\delta_{\mathrm{C}}: 39.94,55.94,113.11,113.97,114.03,114.09,114.11,115.19, \\
115.31,115.96,120.12,121.1,130.21,133.85,137.47,145.21,147.35, \\
148.25,148.31,149.7,151.7 \mathrm{ppm} .\end{array}$ \\
\hline Compound $\mathbf{3}$ & $\begin{array}{c}\delta_{\mathrm{H}}: 0.96(\mathrm{~s}, 6 \mathrm{H}), 1.16-2.28(\mathrm{~m}, 8 \mathrm{H}), 2.50(\mathrm{broad}, 2 \mathrm{H}) \\
2.54-2.62(\mathrm{~m}, 4 \mathrm{H}), 2.68-2.72(\mathrm{~m}, 2 \mathrm{H}), 2.94(\mathrm{~m}, 2 \mathrm{H}), 3.30 \\
(\mathrm{~m}, 2 \mathrm{H}), 3.84(\mathrm{~s}, 6 \mathrm{H}), 5.34(\mathrm{~d}, \mathrm{~d}, 2 \mathrm{H}), 6.16-7.18(\mathrm{~m}, 9 \mathrm{H}) \\
\text { ppm. }\end{array}$ & $\begin{array}{c}\delta_{\mathrm{C}}: 9.95,32.28,33.91,36.9,37.59,47.33,55.94,71.30,112.19,113.18, \\
113.34,114.11,115.19,115.31,120.46,121.44,129.7,133.32,133.85, \\
145.21,146.1,147.08,147.62,147.68,149.7,151.42 \mathrm{ppm} .\end{array}$ \\
\hline
\end{tabular}




\section{Biological Activity}

\section{First Stage}

In the Figure 2 is showed the biological activity exerted by the compound $\mathbf{3}$ on ischemia/reperfusion injury; the results showed that compound 3 reduce area of infarction to different dose [0.001 to $100 \mathrm{nM}$ ].

Other results (Figure 3 ) indicate that compound $\mathbf{3}$ significantly $(\boldsymbol{p}=0.05)$ reduces infarct size expressed as a percentage of the area at risk compared with 2,4-dinitrofluorobenzene, the compound $\mathbf{2}$ and vehicle treated hearts (control).

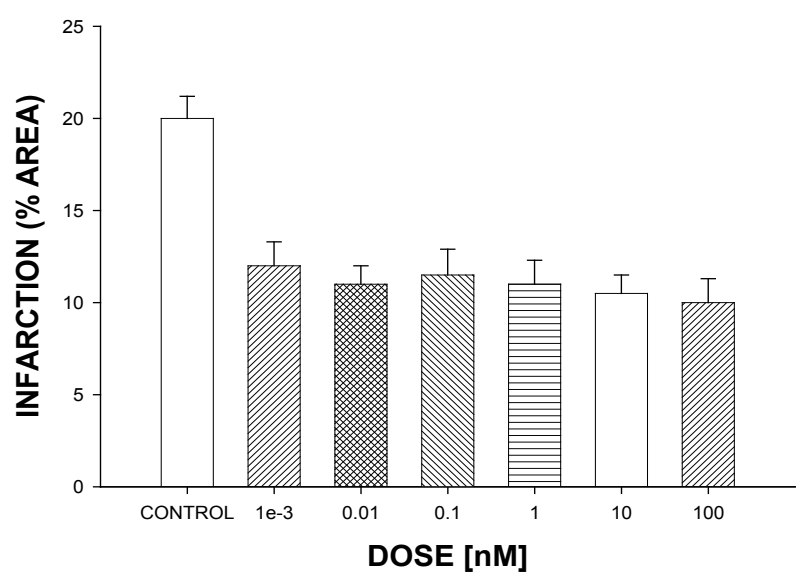

Figure 2. Biological activity exerted by compound 3 at a dose of 0.001 (1e-3) to $100 \mathrm{nM}$ on the functional recovery of rat hearts subjected to ischemia and reperfusion. The results indicate that the compound 3 reduce the area infarct to different dose compared with control conditions.

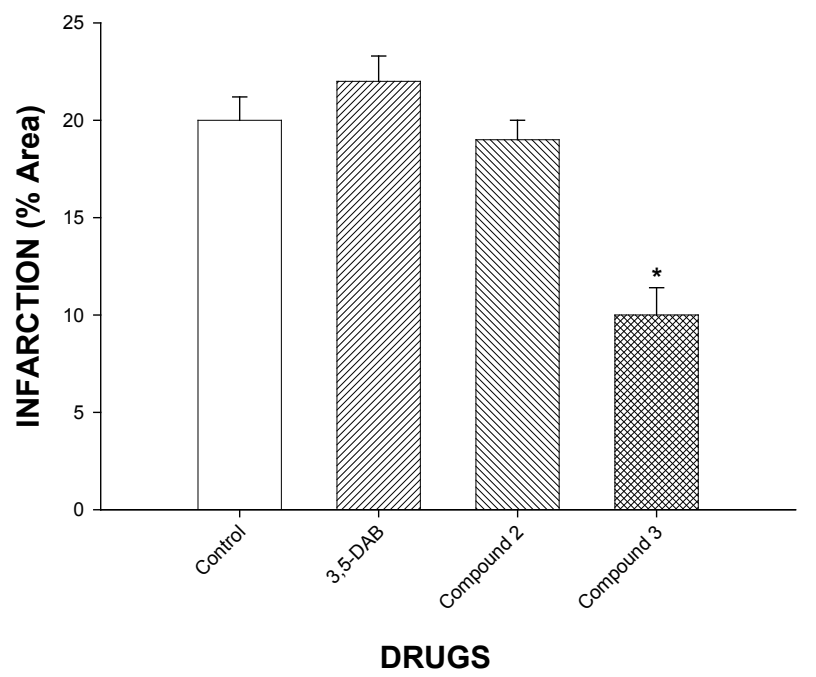

Figure 3. Biological activity exerted by compound $\mathbf{3}$ or 2,4-dinitrofluorobenzene (2,4-DNFB) or compound 2 at dose of $0.001 \mathrm{nM}$ on the functional recovery of rat hearts subjected to ischemia and reperfusion. The results indicate that the compound $\mathbf{3}$ significantly reduce $(\boldsymbol{p}=0.05)$ the area infarct to different dose compared with 2,4-DNFB, compound $\mathbf{2}$ and control conditions.

\section{Second Stage}

The activity induced by 2,4-dinitrofluorobenzene, the compounds $\mathbf{2}$ and $\mathbf{3}$ on perfusion pressure and coronary resistance in the isolated rat hearts was evaluated (Figure 4). The showed that compound $\mathbf{3}(\boldsymbol{p}=0.05)$ significantly increase the perfusion pressure in comparison with 2,4-dinitrofluorobenzene, compound $2[0.001 \mathrm{nM}]$ and control conditions. 


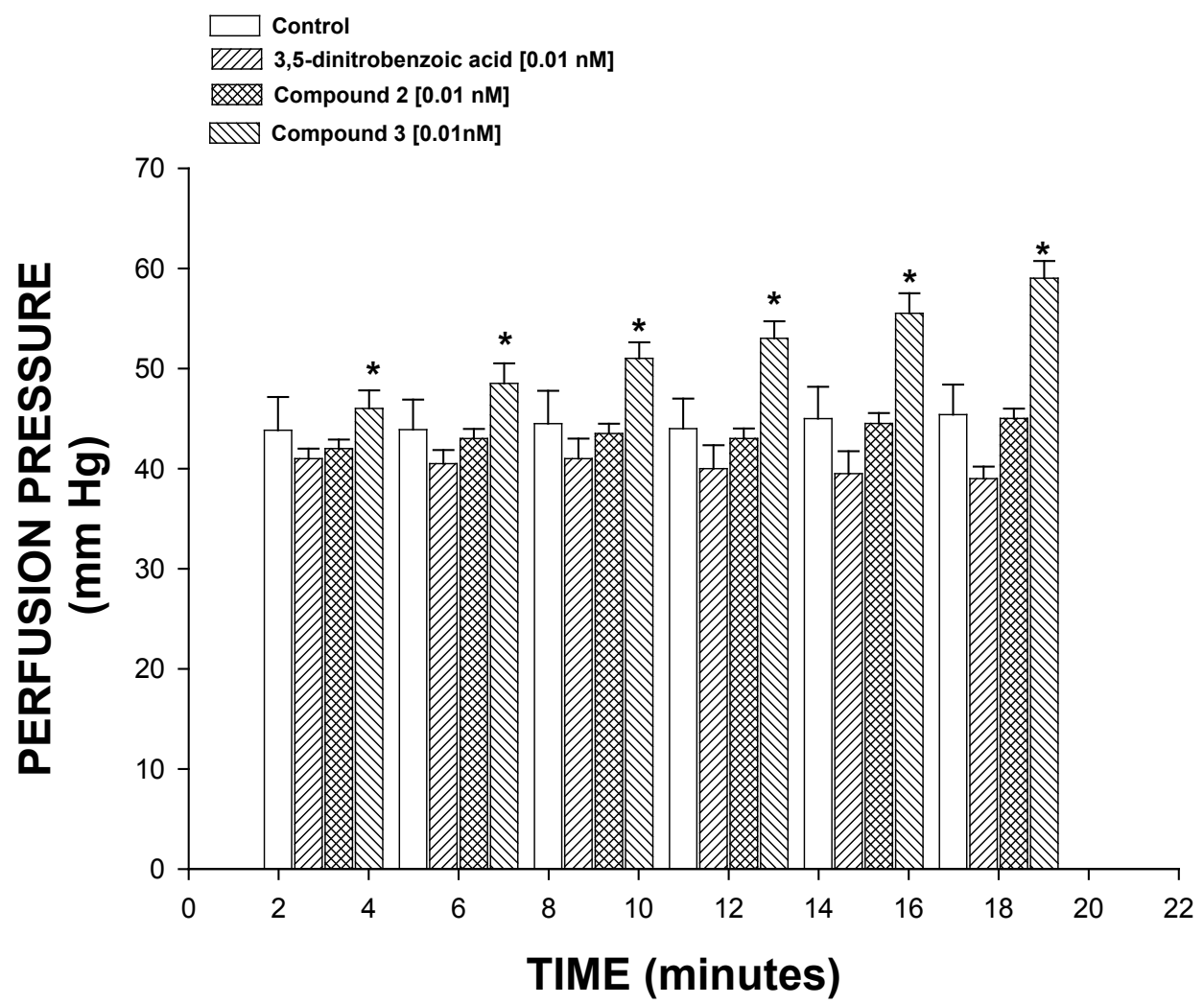

Figure 4. Effect induced by the compounds $\mathbf{2}$ or $\mathbf{3}$ or 2,4-dinitrofluorobenzene on perfusion pressure. The results showed that the compound $\mathbf{3}$ significantly increase perfusion pressure $(p=0.05)$ in a manner dependent of time in comparison with 2,4-dinitrofluorobenzene, the control conditions and compound 2. Each bar represents the mean \pm S.E. of 9 experiments.

In addition, the coronary resistance (Figure 5), calculated as the ratio of perfusion pressure at coronary flow assayed (10 $\mathrm{ml} / \mathrm{min})$ was significantly higher $(\boldsymbol{p}=0.05)$ in presence of the compound $\mathbf{3}[0.001 \mathrm{nM}]$ in comparison with 2,4-dinitrofluorobenzene or the compounds 2 and control conditions.

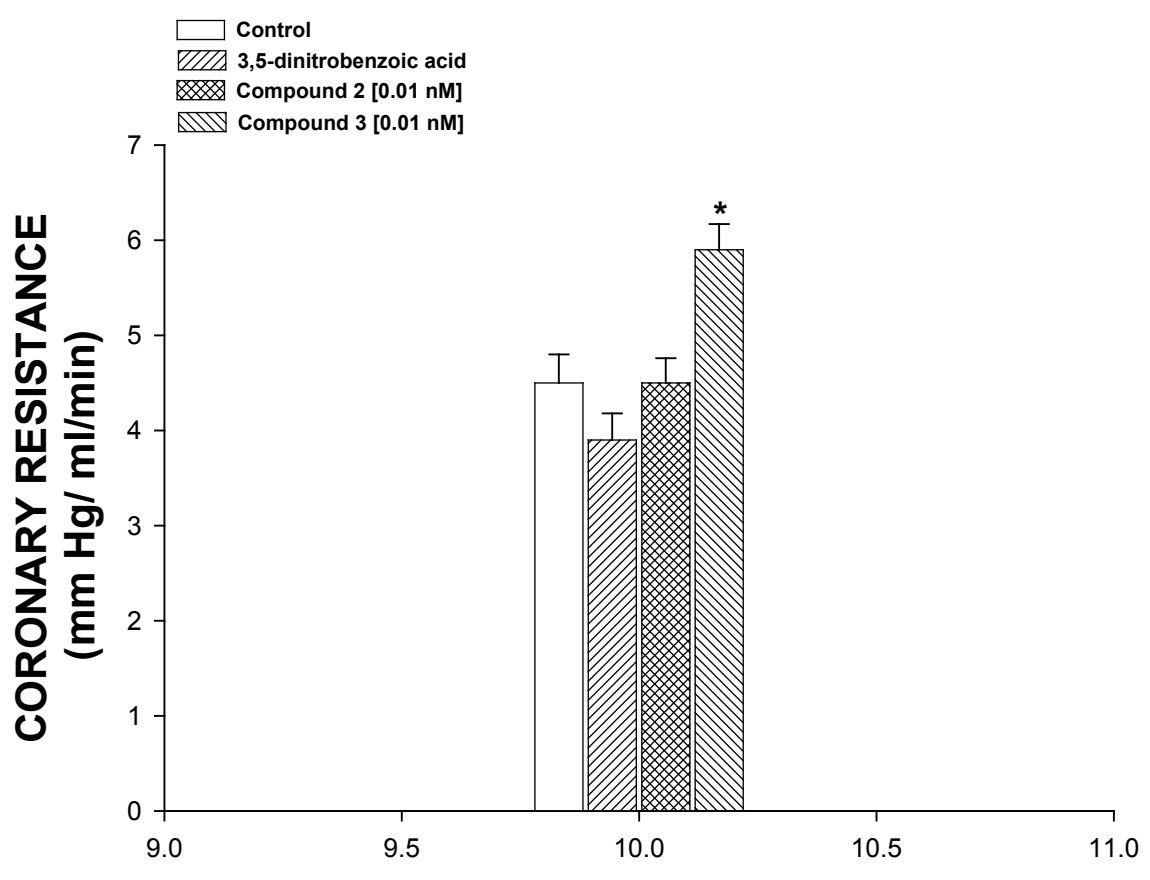

FLOW CORONARY (ml/min)

Figure 5. Biological activity exerted by the compound 3 or 2,4-dinitrofluorobenzene or compound 2 at dose of $0.001 \mathrm{nM}$ on coronary resistance. The results showed that coronary resistance was higher $(p=0.05)$ in the presence of the compound 3 compared with 2,4-dinitrofluorobenzene acid, the control conditions and compound 2. Each bar represents the mean \pm S.E. of 9 experiments. 


\section{Third Stage}

The Figure 6 show that perfusion pressure was significantly higher $(p=0.05)$ in presence of the compound 3 compared with norepinephrine and dobutamine in a manner dependent of time.

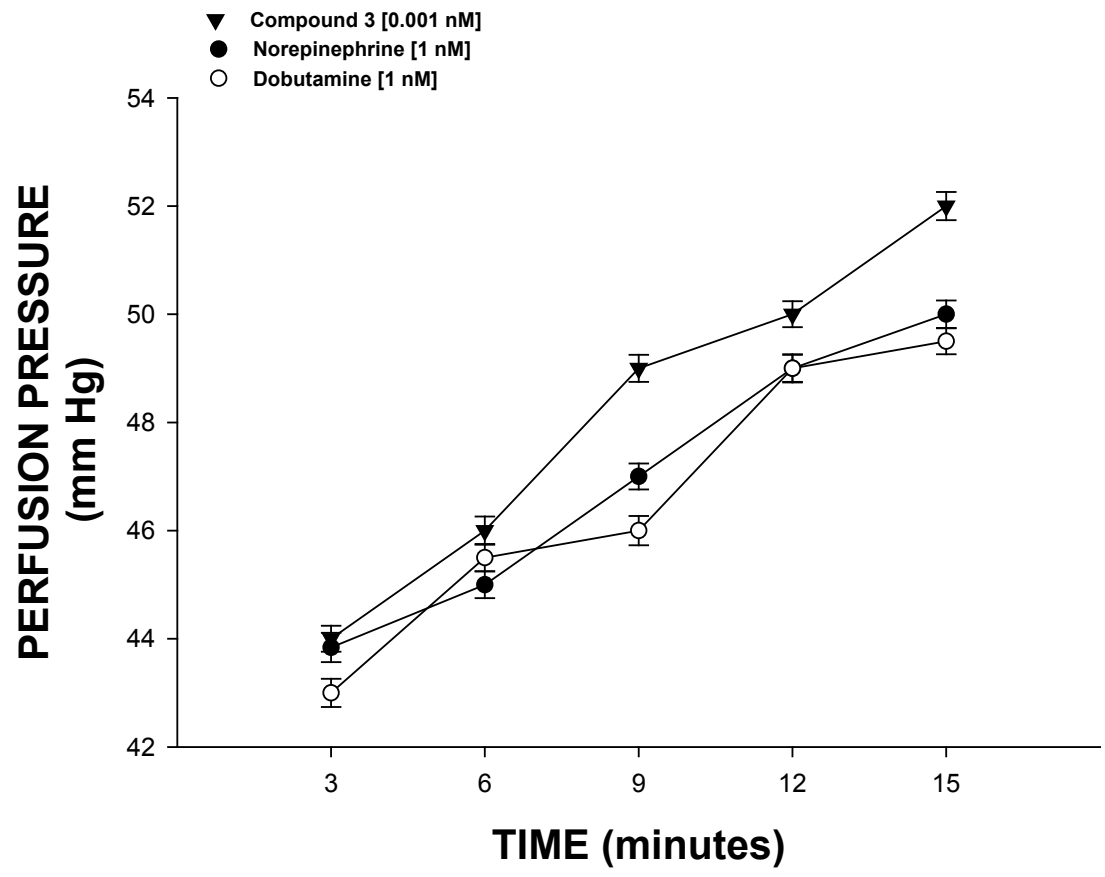

Figure 6. Biological activity exerted by norepinephrine, dobutamine and the compound $\mathbf{3}$ on perfusion pressure in a manner dependent of time. The results showed that perfusion pressure was significantly higher $(p=0.05)$ in presence of the compound 3 compared with norepinephrine and dobutamine. Each bar represents the mean \pm S.E. of 9 experiments.

In addition, the Figure 7 showed that biological activity of the compound $\mathbf{3}$ on perfusion pressure was similar compared with digoxin and ouabain; however, significantly different $(\boldsymbol{p}=0.05)$ to levosimendan and this effect was inhibited $(\boldsymbol{p}=$ 0.05 ) by cyclopiazonic acid and thapsigargin (Figure 8 ).

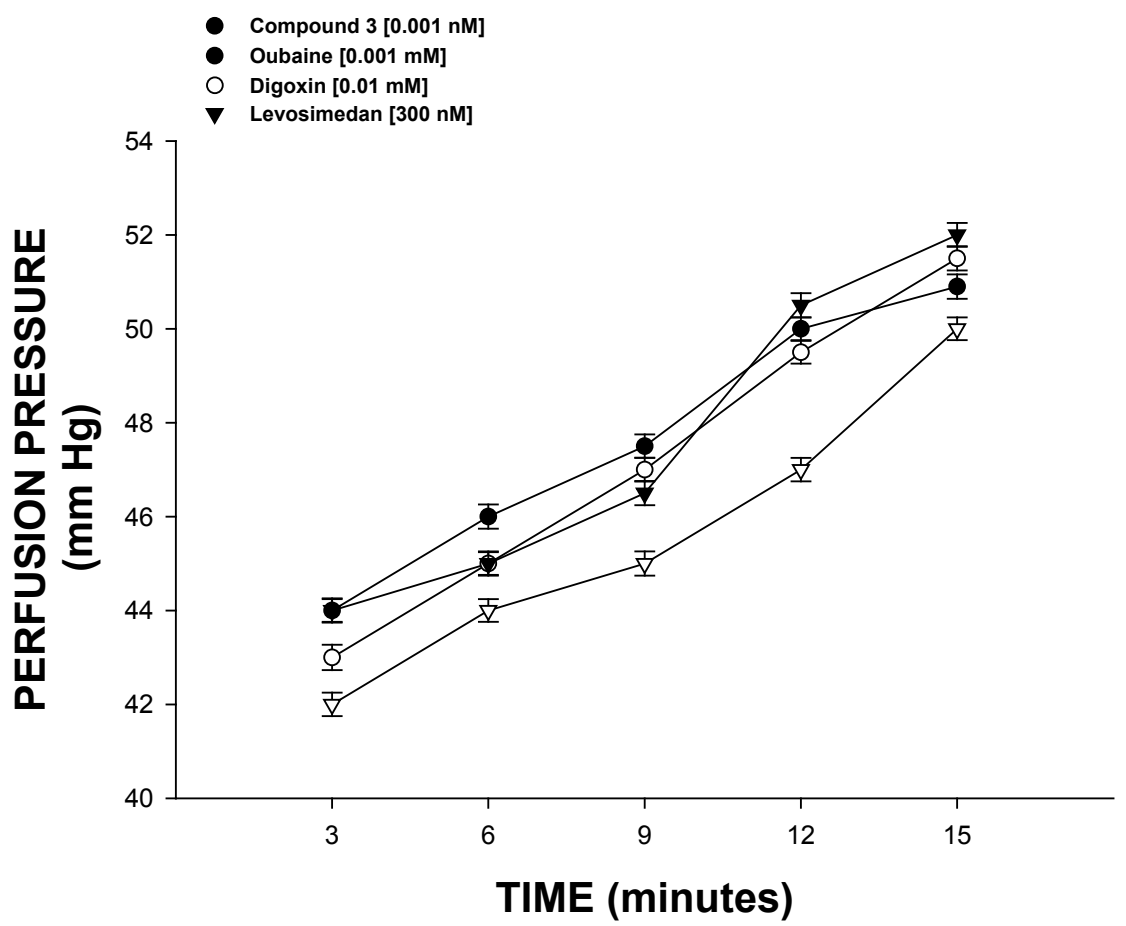

Figure 7. Effect induced by digoxin, ouabain, levosimendan and the compound $\mathbf{3}$ on perfusion pressure in a manner dependent of time. The results showed that compound $\mathbf{3}$ increasing the perfusion pressure through of time in a similar form that digoxin and ouabain. In addition this effect was significantly different $(\boldsymbol{p}=0.05)$ that levosimendan. Each bar represents the mean \pm S.E. of 9 experiments. LVP $=$ left ventricular pressure 


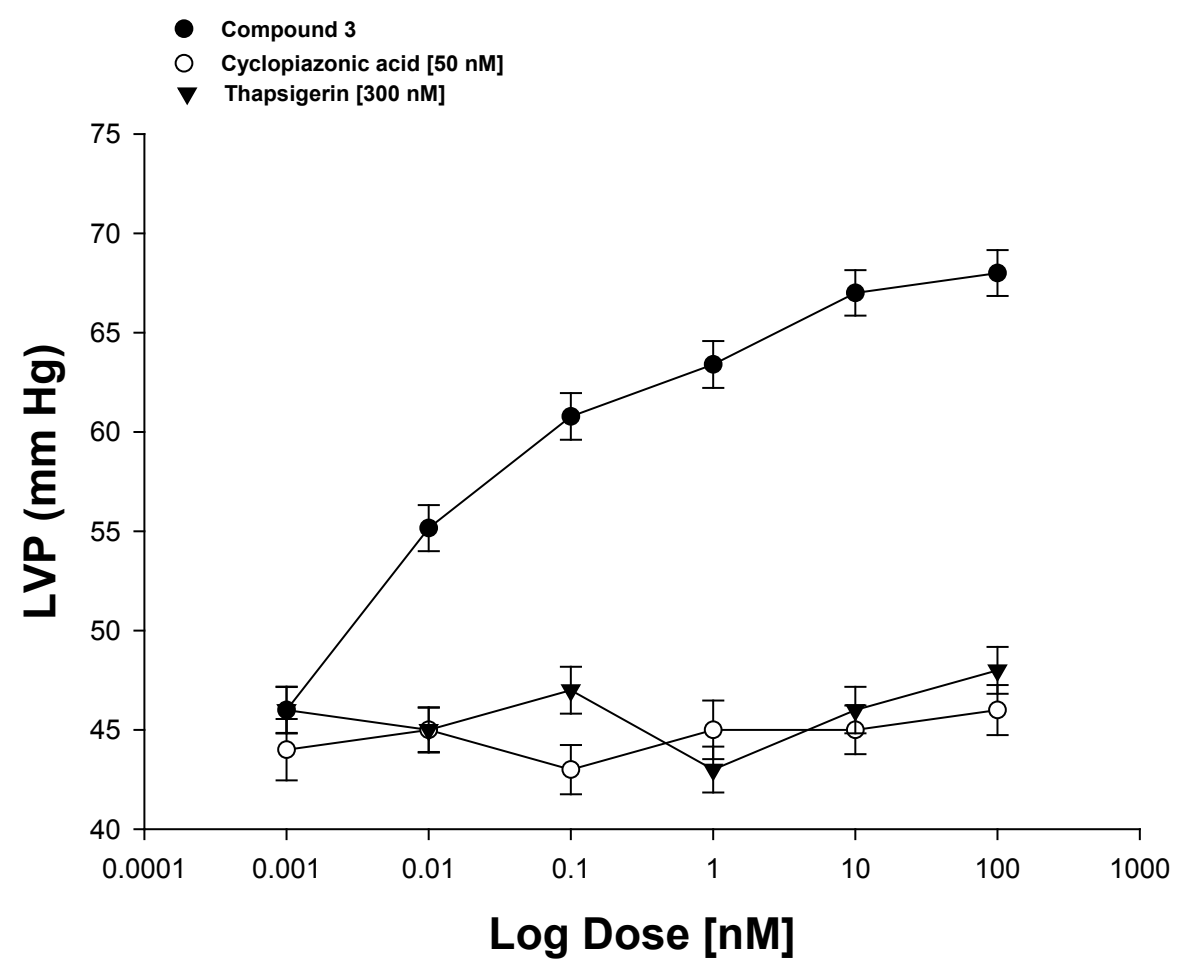

Figure 8. Intracoronary boluses $(50 \mu \mathrm{l})$ of the compound $\mathbf{3}[0.001$ to $100 \mathrm{nM}]$ were administered and the corresponding effect on the LVP was determined in the absence and presence of cyclopiazonic acid or thapsigargin. The results showed that compound $\mathbf{3}$ increase the LVP in a dependent dose manner and this effect was significantly inhibited $(\boldsymbol{p}=0.05)$ in the presence of cyclopiazonic acid and thapsigargin. Each bar represents the mean \pm S.E. of 9 experiments. LVP $=$ left ventricular pressure.

Other data showed (Figures 9 and 10) the interaction of the compound 3 with amino acids residues of both $\mathrm{K}$,Na-ATP-ase and $\mathrm{Ca}^{+2}$-ATP-ase

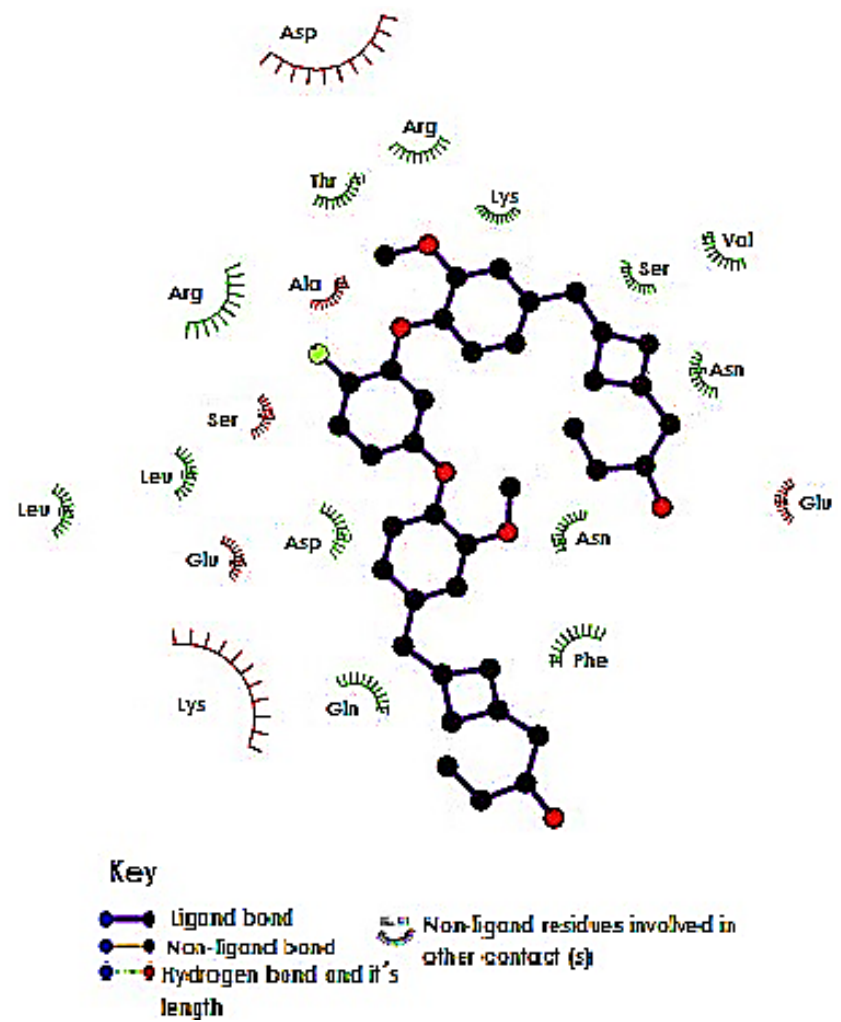

Figure 9. Interaction of the K,Na-ATP-ase (1KJU) surface with the compound 3. The scheme shown the contact site of amino acid residues involved in the interaction of K,Na-ATP-ase with 3. Visualized with GL mol, viewer after docking analysis with one-click docking. 

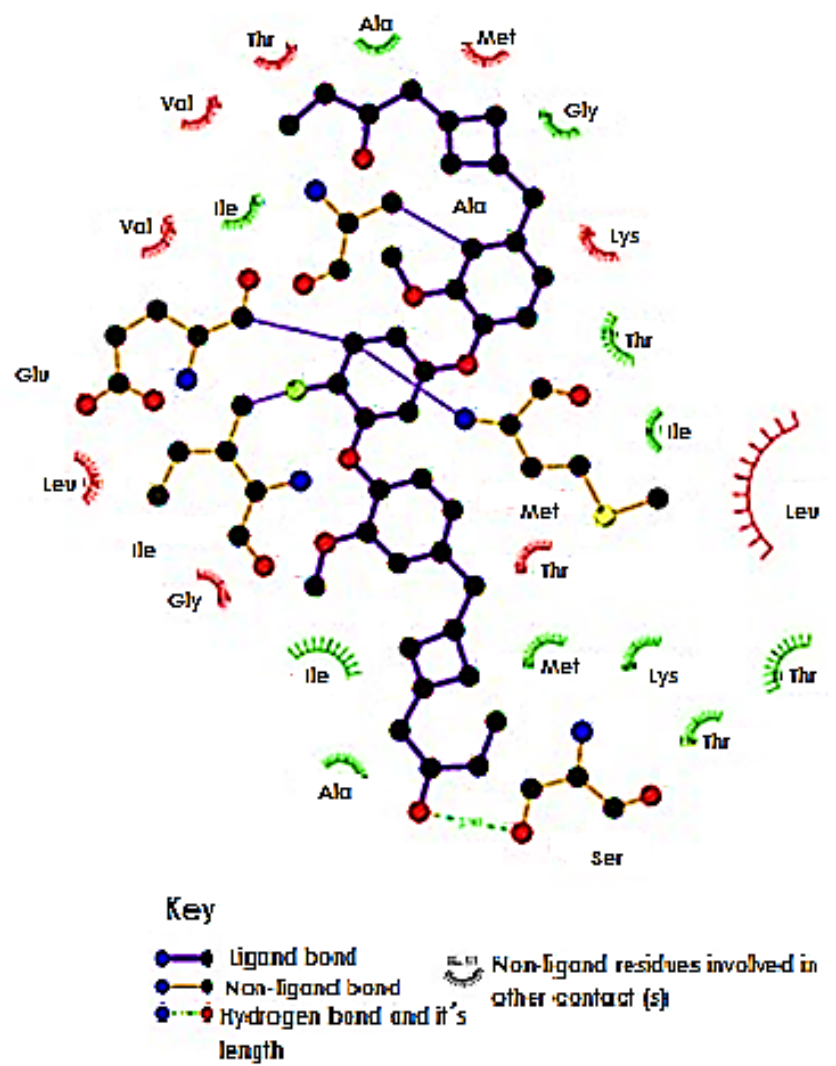

Figure 10. Interaction of the $\mathrm{Ca}^{+2}-\mathrm{ATP}$-ase ( $3 \mathrm{WGU}$ ) surface with the compound 3 . The scheme shown the contact site of amino acid residues involved in the interaction of $\mathrm{Ca}^{+2}$-ATP-ase with 3 . Visualized with GL mol, viewer after docking analysis with one-click docking.

\section{Discussion}

\section{Chemical Synthesis}

In this study we report a straight forward route for the preparation of a

fluorobenzene-2,3-methoxy-di-phenoxycy- clobuten-diol derivative (compound $\mathbf{3}$ ) using some strategies. The First stage was achieved by the preparation of a fluoro-methoxy-benzene derivative (compound 2) by the reaction of 2,4-dinotrofluorobenzene with eugenol in basic medium. Then 2 was reacted with 1-hexyn-3-ol using CopperII as catalyst to form 3 . The structure of the compounds $\mathbf{2}$ and $\mathbf{3}$ was confirmed using NMR spectroscopy (Table 1).

\section{Biological Evaluation}

There are several reports which indicate that some fluoro-benzene derivatives exert effects on cardiovascular system [25]; however, the cellular site and molecular mechanism involved in its inotropic activity are very confusing; perhaps this phenomenon is due to differences in the chemical structure of fluoro-benzene derivatives or to the different pharmacological approaches used.
Analyzing this hypothesis, in this study the biologic activity of the compound $\mathbf{3}$ on reperfusion/injury was evaluated using an isolated heart model. The results (Figure 2) showed that the compound $\mathbf{3}$ reduced infarct size (expressed as a percentage of the area at risk) to different dose. For evaluate whether the activity exerted by compound 3 could depend on the functional groups involved in its chemical structure; therefore, in this study, also the effect of 2,4-dinitrofluorobenzene and the compound 2 on reperfusion/injury was evaluated. The results showed that only the compound $\mathbf{3}$ significantly reduce the infarction area compared with 2,4-dinitrofluorobenzene and the compound 2, these data indicate that functional groups of the compound $\mathbf{3}$ are responsible of their biological activity; these phenomenon could be the result of activation of some structure biological (p.e. ionic channels or specific receptors) involved in the endothelium of coronary artery; or 3) possibly by the influence exerted by the compound $\mathbf{3}$ on blood pressure which results as a reduction in the infarct size, and decrease the myocardial injury after ischemia-reperfusion. Analyzing this hypothesis and other reports $[35,36]$ which indicate that some compounds reduce the infarct area by induce changes on perfusion pressure; in this study, the biological activity of compounds 2,4-dinitrofluorobenzene, $\mathbf{2}$ and $\mathbf{3}$ on perfusion pressure was evaluated in an isolated rat heart model. The results show that only the compound $\mathbf{3}$ significantly increases the perfusion pressure over time compared with compounds 2,4-dinitrofluorobenzene, or $\mathbf{2}$ and the control conditions. This phenomenon, indicate that compound $\mathbf{3}$ exerts effects on perfusion pressure which could translated as changes in the vascular tone and coronary resistance of heart. To evaluate this hypothesis, the activity exerted by the compounds 2,4-dinitrofluorobenzene, $\mathbf{2}$ and $\mathbf{3}$ on coronary resistance was evaluated. The results indicate that only the compound $\mathbf{3}$ exert biological activity on coronary resistance in comparison with the compounds 2,4-dinitrofluoro-benzene or $\mathbf{2}$ and the control conditions.

Analyzing these data and other reports which indicate that phenylephrine and dobutamine exert changes on perfusion pressure [37, 38]; in this study, the biological activity of phenylephrine, dobutamine and compound 3 was evaluated to analyze the possibly molecular mechanism involved in the effect exerted by the compound 3 on perfusion pressure. The results showed that compound significantly increased the perfusion pressure in comparison with phenylephrine and dobutamine; this phenomenon, suggest that molecular mechanism involved in the effect exerted on perfusion pressure was not via adrenergic.

Analyzing this data and other studies which indicate that digoxin and ouabain (Na/K-ATPase inhibitors) exert biological activity on perfusion pressure [39]; in this study, the effect exerted by compound 3 on perfusion pressure was compared with the activity of these cardiac glucosides. 
The results showed that biological activity of compound $\mathbf{3}$ on perfusion pressure was similar to both digoxin and ouabain; these data indicated that compound 3 could exert their inotropic activity via $\mathrm{Na} / \mathrm{K}-\mathrm{ATPase}$ inhibition; it is noteworthy, that some reports indicate that Na,K-ATPase is a regulator of intracellular calcium in the heart [40]. Here it is important to mention that also the $\mathrm{Ca}^{+2}$-ATPase can modulates cardiac contraction and this phenomenon can be inhibited by both cyclopiazonic acid and thapsigargin. Analyzing these data, in this study the biological activity of compound 3 on left ventricular pressure was evaluated in absence or presence of both cyclopiazonic acid and thapsigargin. The results indicate that inotropic activity exerted by the compound $\mathbf{3}$ was inhibited in presence of cyclopiazonic acid and thapsigargin. All these data indicate that the compound $\mathbf{3}$ exert a positive inotropic on perfusion pressure and left ventricular pressure via changes of biological activity both $\mathrm{Na}, \mathrm{K}$-ATPase and $\mathrm{Ca}+2$-ATPase, this phenomenon could be similar to effect induced by the palmitoycarnitine in an isolated dog heart model [41].

\section{Docking Evaluation}

To evaluate the possibility of compound $\mathbf{3}$ interacting with both ATPases (Na,K-ATPase and $\mathrm{Ca}^{+2}$-ATPase), in this study we used a model of molecular coupling (serverdoking) $[29,30]$. In the Figure 9 shown theoretical results on hydrogen-interaction between compound $\mathbf{3}$ and $\mathrm{Na}, \mathrm{K}-\mathrm{ATPase}$ (3WGU) which involves several amino acid residues such as $\mathrm{Glu}_{244}, \mathrm{Thr}_{371}, \mathrm{Leu}_{449}, \mathrm{Phe}_{475}, \mathrm{Asn}_{476}$, $\mathrm{Ser}_{477}, \mathrm{Lys}_{480}, \mathrm{Gl}_{482}, \mathrm{Lys}_{501}, \mathrm{Ala}_{503} \cdot \mathrm{Arg}_{544}, \mathrm{Leu}_{546}, \mathrm{Asp}_{612}$, $\operatorname{Arg}_{685}, \operatorname{Val}_{712}$ and $\mathrm{Asn}_{713}$. Other data, showed (Figure 10) that interaction between the compound $\mathbf{3}$ and $\mathrm{Ca}^{+2}$-ATPase $(1 \mathrm{KJU})$ involved some amino acid residues such as $\mathrm{Thr}_{323}$, $\mathrm{Met}_{326}, \mathrm{Ala}_{327}, \mathrm{Lys}_{329}, \mathrm{Ala}_{331}, \mathrm{Val}_{333}, \mathrm{Val}_{339}, \mathrm{Leu}_{342}$, $\mathrm{Thr}_{345} . \mathrm{Ile}_{348}, \mathrm{Ser}_{350}, \mathrm{Thr}_{355}, \mathrm{Leu}_{356}, \mathrm{Ala}_{699}, \mathrm{Thr}_{701}, \mathrm{Ile}_{716}$, $\mathrm{Gly}_{717}, \mathrm{Ile}_{718}, \mathrm{Met}_{720}, \mathrm{Glu}_{732}, \mathrm{Met}_{733}, \mathrm{Leu}_{735}, \mathrm{Thr}_{742}, \mathrm{Glu}_{749}$ and $\mathrm{Ile}_{753}$. All these data indicate that interaction of compound 3 with ATPases is via interaction of different amino acid residues which is translated as increase in the positive inotropic activity compared with ouabain and digoxine.

\section{Conclusions}

\section{The}

fluorobenzene-2,3-methoxy-di-phenoxycyclobuten-diol derivative (compound $\mathbf{3}$ ) is a particularly interesting drug, because its positive inotropic activity exerted on perfusion pressure involves a molecular mechanism different in comparison with other drugs; this phenomenon may constitute a novel therapy for heart failure.

\section{Acknowledgements}

None.

\section{REFERENCES}

[1] Cleland J, Clark A. Has the survival of the heart failure population changed? Lessons from trials. Am. J. Cardiol. 1999; 83:112D-9.

[2] Lobos J, Díaz S, Redondo R. Evaluación de la insuficiencia cardíaca desde la consulta de atención primaria. Form. Med. Contn. Aten. Prim. 1997;4:10-23.

[3] Boix M, Almazán I, Medrano A. Mortalidad por insuficiencia cardíaca en España, 1977-1998. Rev. Esp. Cardiol. 2002;55:219-26.

[4] Lechat P, Packer M, Chalon S, Cucherat M, Arab T, Boissel J. Clinical effects of beta-adrenergic blockade in chronic heart failure: A meta-analysis of double-blind, placebo-controlled, randomized trials. Circulation. 1998;98:1184-91

[5] Carson P. Blocker therapy in heart failure: Pathophysiology and clinical results. Curr. Probl. Cardiol. 1999; 24:426-60.

[6] Mendéz R. Doscientos años de digital. Arch. Inst. Cardiol. Mex. 1986; 56: 339-48.

[7] Tischler M, Smith T. Digitalis: Its current place in the treatment of heart failure. Modern. Conc. Cardiovasc. Dis. 1990; 59: 67-72.

[8] Ahmed A, Rich M, Fleg J, Zile M, Young J, Kitzman D. Effects of digoxin on morbidity and mortality in diastolic heart failure. Circulation. 2006; 114: 397-403.

[9] Mayes J, Carter C, Adams J. Inotropic therapy in the home care setting: Criteria, management, and implications. J. Intraven. Nurs. 1995; 18: 301-306.

[10] Follath F, Cleland J, Just H, Papp J, Scholz H, Peuhkurinen $\mathrm{K}$. Steering Committee and Investigators of the Levosimendán Infusion versus Dobutamine (LIDO) Study. Efficacy and safety of intravenous levosimendán compared with dobutamine in severe low-output heart failure (the LIDO study): A randomized double-blind trial. Lancet. 2002; 360:196-202.

[11] Papp J. Introduction: Positive inotropy by calcium sensitization-an evolving approach for the treatment of end-stage heart failure. Am. J. Cardiol. 1999; 83: 1-3.

[12] Corvalán H, Casanegra P, Chamorro S, Jalil M, Valenzuela P. Comparación de los efectos clínicos y neurohumorales de milrinona y captopril en pacientes con insuficiencia cardíaca crónica. Bol. Cardiol. Chile. 1988; 7: 289-300.

[13] Bregagnollo E, Fortes AH, Cicogna AC. Avaliação dos efeitos inotrópicos e vasodilatadores do lactato de milrinona em pacientes com cardiomiopatia dilatada e insuficiência cardíaca grave. Arq. Brás. Cardiol. 1999; 72: 149-54.

[14] Cosín A, Hernández M. Ensayos clínicos en insuficiencia cardíaca. Esp. Cardiol. 2001; 54:22-31.

[15] Hoffman TM, Wernovsky G, Atz AM, Kulik TJ, Nelson DP, Chang AC. Efficacy and safety of milrinone in preventing low cardiac output syndrome in infants and children after corrective surgery for congenital heart disease. Circulation 
2003; 107: 996-1002.

[16] Gol V, Barroso P. Farmacología de la insuficiencia cardíaca. Farm. Hosp. 1996; 20:149-56.

[17] The Consensus Trial Study Group. Effects of enalapril on mortality in severe congestive heart failure. Results of the cooperative north Scandinavian enalapril survival study (CONSENSUS). N. Engl. J. Med. 1987; 316: 1429-35.

[18] The SOLVD Investigators. Effect of enalapril on survival in patients with reduced left ventricular ejection fractions and congestive heart failure. N. Engl. J. Med. 1991; 325: 293-302.

[19] Tamargoa J, López J. Avances en el tratamiento de la insuficiencia cardíaca. IV - Bases y evidencias clínicas de los efectos de los nuevos tratamientos farmacológicos en la insuficiencia cardíaca. Rev. Esp. Cardiol. 2004; 57: 447-64.

[20] Pitt B, Zannad F, Remme WJ, Cody R, Castaigne A, Pérez A. The effect of spironolactone on morbidity and mortality in patients with severe heart failure. Randomized aldactone evaluation study investigators. N. Engl. J. Med. 1999; 341:709-17.

[21] Juurlink D, Mamdani M, Lee DS, Kopp A, Austin P, Laupacis A. Rates of hyperkalemia after publication of the randomized aldactone evaluation study. N. Engl. J. Med. 2004; 351: 543-51.

[22] David W. Robertson, Joseph H. Krushinski, G. Don Pollock, Harve Wilson, Raymond F. Kauffman, J. Scott Hayes. Dihydropyridazinone cardiotonics: synthesis and inotropic activity of 5'-(1,4,5,6-tetrahydro-6-oxo-3-pyridazinyl)spiro[cycloalkane-1,3'-[3H]indol]-2'(1'H)-ones. J. Med. Chem. 1987; 30 (5): 824-829.

[23] Wu Zhenjiu, Takeo Awaji, Humiaki Abe, Shigeru Motomura, Keitaro Hashimoto. Effects of OPC-18790, a New Positive Inotropic Agent, on Canine Ventricular Arrhythmias. The Japanese J. Pharmacol. 1993; 63(3): 399-404.

[24] Kang Y, Koo E, Lee Y, Sook Y, Ki C. Prevention of the expression of inducible nitric oxide synthase by a novel positive inotropic agent, YS 49, in rat vascular smooth muscle and RAW 264.7 macrophages. British J. Pharmacol. $1999 ; 128: 357-364$.

[25] Baker N, Byrne N. Studies on New Phosphodiesterase Inhibitors. I. Synthesis of 1-(2,3-Epoxypropoxy)-2(4)fluorobenzenes and 1-(2-Hydroxy-3-morpholinopropoxy and Piperazino) fluorobenzene Derivatives. Chem. Pharm. Bull. 1995; 43(5) 1045-1048.

[26] Figueroa-Valverde L， Diaz-Ku L， Diaz-Cedillo F, Baqueiro-Bricaire A, Camacho-Luis A. Effects of danazol and danazol hemisuccinate on perfusión pressure and vascular resistance. Acta Bioquím. Clín. Latinoam. 2010; 44 (1): $37-45$.

[27] Boe J, Khan B. Colorimetrie determination of blood calcium. J. Biol. Chem. 1928; 81:1-8.

[28] Booth E, Obeid N, Lucchesi B. Activation of estrogen receptor- $\alpha$ protects the in vivo rabbit heart from ischemia-reperfusion injury. Am. J. Physiol. Heart, Circul. Physiol. 2005;289:H2039-H2047

[29] Liu R, Perez J, Liang D, Saven J (2012) Binding site and affinity prediction of general anesthetics to protein targets using docking. Anesth. Analg. 114:947-955 43.

[30] Rosales M, Correa J. The importance of employing computational resources for the automation of drug discovery. Expert Op. Drug Dis. 2015; 10:213-219.

[31] Yan Y, Shapiro A, Mopidevi B, Chaudhry M, Maxwell K. Protein Carbonylation of an Amino Acid Residue of the $\mathrm{Na} / \mathrm{K}$ - ATPase $\alpha 1$ Subunit Determines $\mathrm{Na} / \mathrm{K}$ - ATPase Signaling and Sodium Transport in Renal Proximal Tubular Cells. J. Am. Heart Assoc. 2016;5:e003675

[32] Chen L, Yao Q, Soares T, Squier T, Bigelow D. Phospholamban Modulates the Functional Coupling between Nucleotide Domains in Ca-ATPase Oligomeric Complexes in Cardiac Sarcoplasmic Reticulum. Biochemistry. 2009 Mar 24; 48(11): 2411-2421.

[33] Solis F (1981) Minimization by random search techniques. Mathem Meth Oper Res 6: 19-30.

[34] Hocht C, Opezzo J, Gorzalczany S (1999) Una Aproximación Cinética y Dinámica de Metildopa en Ratas con Coartación Aórtica Mediante Microdiálisis. Rev Arg Cardiol 67, 769-773.

[35] Sarabia-Alcocer B, Figueroa-Valverde L, Díaz-Cedillo F, Hau-Heredia L, Rosas-Nexticapa M, García-Cervera E, Pool-Gómez E, García-Martínez R, Zepeda-Acosta B. Activity Induced by a Naphthalene-Prazosin Derivative on Ischemia/Reperfusion Injury in Rats. Pharmacology \& Pharmacy, 5, 1130-1142.

[36] Figueroa-Valverde L, Díaz-Cedillo F, García-Cervera E, Pool Gómez E, López-Ramos M, Rosas-Nexticapa M, Martinez-Camacho R. Positive inotropic activity induced by a dehydroisoandrosterone derivative in isolated rat heart model. Arch. Pharm. Res. 2013; 36 (10) 1270-1278.

[37] Tsutomu T, Shigetoshi C. Potentiating Effect of Methysergide on Norepinephrine-Induced Constriction of the Isolated Internal Carotid Artery of the Dog. Japanese J. Pharmacol. 1984; 34(1): 95-100.

[38] Kerbaul F, Rondelet B, Motte S. Effects of norepinephrine and dobutamine on pressure load-induced right ventricular failure. Critical Care Med. 2004; 32(4) 1035-1040.

[39] Akera T, Baskin S, Tobin T, Brody T. Quabain: Temporal relationship between the inotropic effect and the in vitro binding to, and dissociation from, $\left(\mathrm{Na}^{+}+\mathrm{K}^{+}\right)$-activated ATPase. Naunyn-Schm. Arch. Pharmacol. 1973; 277(2):151-162

[40] James P, Woo A, Askew R, Croyle M, Walsh R, Lingre J. Identification of a Specific Role for the Na, K-ATPase a2 Isoform as a Regulator of Calcium in the Heart. Mol. Cell, $1999 ; 3 ; 555-563$.

[41] Abe M, Yamazaki N, Suzuki Y, Kobayashi A, Ko H. Effect of palmitoyl carnitine on $\mathrm{Na}^{+}, \mathrm{K}^{+}$-ATPase and adenylate cyclase activity of canine myocardial sarcolemma. J. Mol. Cell. Cardiol. 1984; 16(3): 239-245. 